\title{
Nutraceutical Aid for Allergies - Strategies for Down-Regulating Mast Cell Degranulation
}

\author{
Mark F McCarty' \\ Aaron Lerner (iD ${ }^{2}$ \\ James J DiNicolantonio ${ }^{3,4}$ \\ Carina Benzvi² \\ 'Catalytic Longevity Foundation, San \\ Diego, CA, USA; ${ }^{2}$ Chaim Sheba Medical \\ Center, The Zabludowicz Research \\ Center for Autoimmune Diseases, Tel \\ Hashomer, Israel; ${ }^{3}$ Saint Luke's Mid \\ America Heart Institute, Kansas City, \\ MO, USA; ${ }^{4}$ Advanced Ingredients for \\ Dietary Products, AIDP, City of Industry, \\ CA, USA
}

\begin{abstract}
Interactions of antigens with the mast cell FceRI-IgE receptor complex induce degranulation and boost synthesis of pro-inflammatory lipid mediators and cytokines. Activation of spleen tyrosine kinase (Syk) functions as a central hub in this signaling. The tyrosine phosphatase SHP-1 opposes Syk activity; stimulation of NADPH oxidase by FceRI activation results in the production of oxidants that reversibly inhibit SHP-1, up-regulating the signal from Syk. Activated AMPK can suppress Syk activation by the FceRI receptor, possibly reflecting its ability to phosphorylate the FceRI beta subunit. Cyclic GMP, via protein kinase G II, enhances the activity of SHP-1 by phosphorylating its C-terminal region; this may explain its inhibitory impact on mast cell activation. Hydrogen sulfide $\left(\mathrm{H}_{2} \mathrm{~S}\right)$ likewise opposes mast cell activation; $\mathrm{H}_{2} \mathrm{~S}$ can boost AMPK activity, up-regulate cGMP production, and trigger Nrf2-mediated induction of Phase 2 enzymes - including heme oxygenase-1, whose generation of bilirubin suppresses NADPH oxidase activity. Phycocyanobilin (PCB), a chemical relative of bilirubin, shares its inhibitory impact on NADPH oxidase, rationalizing reported anti-allergic effects of PCB-rich spirulina ingestion. Phase 2 inducer nutraceuticals can likewise oppose the up-regulatory impact of NADPH oxidase on FceRI signaling. AMPK can be activated with the nutraceutical berberine. Highdose biotin can boost cGMP levels in mast cells via direct stimulation of soluble guanylate cyclase. Endogenous generation of $\mathrm{H}_{2} \mathrm{~S}$ in mast cells can be promoted by administering $\mathrm{N}$-acetylcysteine and likely by taurine, which increases the expression of $\mathrm{H}_{2} \mathrm{~S}$-producing enzymes in the vascular system. Mast cell stabilization by benifuuki green tea catechins may reflect the decreased surface expression of FceRI.
\end{abstract}

Keywords: nutraceuticals, mast cell, degranulation, allergy, FceRI-IgE receptor, hydrogen sulfide, phycocyanobilin, berberine, biotin, lipoic acid

\section{Introduction}

Pharmacological strategies are most commonly employed to control mast cell degranulation and its pathogenic consequences. This essay deals with nutraceutical strategies, which may have analogous therapeutic potential. The functions of mast cells and the molecular biology underlying mast cell degranulation will first be described.

\section{Contemporary Insights into Mast Cell Functions}

Mast cell degranulation plays a key role in many human health disorders - not exclusively in allergies. The clinical presentation is wide, involving respiratory, neurologic, digestive, cardiovascular, cutaneous and even musculoskeletal symptoms. ${ }^{1}$ Mast cells contribute to the pathogenesis of infection, cancer,
Chaim Sheba Medical Center, The

Zabludowicz Research Center for

Autoimmune Diseases,

Tel Hashomer, 5262000, Israel

Tel $+972-525-919484$

Email aaronlerner1948@gmail.com 
cardiovascular and many other systemic diseases. ${ }^{2}$ Notably, not only in pathologic conditions, they can play an immunomodulatory role, by secreting anti-antiinflammatory mediators, and thereby impacting the interaction between the immune cells and the environment. ${ }^{1-3}$

Mast cells are endowed with a wide range of plasma membrane receptors, enabling them to sense and react to a plethora of stimuli. The chief receptor triggering mast cell degranulation is the high-affinity $\operatorname{IgE}$ receptor FceRI (Figure 1). A more recently described mast cell receptor capable of provoking degranulation is the Mas-related $\mathrm{G}$ protein-coupled receptor X2 (MRGPRX2), which responds to a range of basic peptides and small proteins, resulting in allergic or neurologic inflammations, pain and itch; hence, there are more receptors that react to drugs, cytokines, complement anaphylatoxins, physical triggers and physical stimuli. ${ }^{1,4}$ Upon sensing endogenous or exogenous danger signals, the activated mast cell releases mediators by three mechanisms. The immediate and rapid one is exocytosis of secretory granules containing pre-synthesized molecules, including histamine, various proteases, heparin, cysteinyl leukotrienes, prostaglandins, and certain proteoglycans. In the second phase, de novosynthesized cytokines, chemokines, interferons and several growth factors can be released independently of the degranulation process. Finally, activated mast cells can secrete extracellular vesicles, such as exosomes, thereby exteriorizing cellular proteins, enzymes, RNAs and miRNAs to the extracellular compartment. ${ }^{1}$

\section{Mast Cell Degranulation Process}

Mast cells can assume a migratory or a secretory behavior, depending on their actin conformation. The secretory actin phenotype supports mobility and exocytosis, in which diaphanous-related formmin, mDia1, plays a major role in intracellular actin rearrangement. ${ }^{1}$ Upon reaching its destination and encountering a secretagogue, mast cell degranulation can be executed in three different modes: full, partial, or the kiss-and-run phenomenon. In the full pathway, the granules can fuse completely with the plasma membrane, in the partial one, they form multiple granules fusion and creating a channel, and the third one implies a transiently fuse with the membrane, releasing part of their content. An additional means of degranulation has been discovered by electron microscopy, namely, piecemeal degranulation. Secretory granules can bud, producing vesicles that are transported to and fused with the plasma membrane. ${ }^{5}$ These varying mechanisms whereby mast cells can release their contents determine the dynamics, intensity and the outcome of degranulation. ${ }^{1}$

A schematic presentation of the mast cells activation is presented in Figure 1.

\section{An Outline of FceRI Receptor Signaling}

The FceRI receptor, whose activation triggers mast cell degranulation and increased production of lipid and cytokine pro-inflammatory mediators, is a heterotetramer that binds tightly to extracellular IgE. ${ }^{6,7}$ The binding of this IgE to specific antigens triggers crosslinking of two RceRI receptor complexes such that src-family tyrosine kinase Lyn bound to each complex can auto-transphosphorylate. These phosphorylations, in turn, enable Lyn to phosphorylate tyrosine residues on the $\gamma$ subunit of the FceRI complex; this enables spleen tyrosine kinase (Syk) to bind to this subunit via its $\mathrm{SH} 2$ domain, and this bound Syk is then activated via phosphorylation by Lyn. Activated Syk then phosphorylates multiple tyrosines on a nearby LAT (linker for activated $\mathrm{T}$ cells) protein, enabling various other proteins to bind to LAT via their $\mathrm{SH} 2$ domains and to promote assembly of a complex signaling platform. Some of these proteins are also phosphorylated by Syk. The resulting signaling platform results in downstream activation of phospholipase $C-\gamma$, phosphatidylinositol-3-kinase (PI3K), IкB kinase, the MAP kinases ERK, JNK, and p38, and NADPH oxidase. ${ }^{6-8}$ These collaborate to promote mast cell degranulation, while boosting synthesis of pro-inflammatory cytokines and lipid mediators. Although the src-family tyrosine kinase Fyn can substitute for Lyn in some of its signaling duties, it is clear that activation of Syk plays a fundamental and essential role in driving mast cell activation. $^{9,10}$

Tyrosine kinase-mediated signaling is opposed and controlled by tyrosine phosphatase activities. Src homology region 2 domain-containing phosphatase 1 (SHP-1) has been shown in mast cells to oppose antigen-induced FceRI signaling; ${ }^{11-14}$ it reverses tyrosine phosphorylations conferred by Syk on LAT and the associated scaffolding protein SLP-76 (Src homology region 2 domaincontaining leukocytes protein of $76 \mathrm{kDa}){ }^{11}$ Notably, SHP-1 is susceptible to reversible inhibition by physiological concentrations of hydrogen peroxide, via conversion of cysteine sulfhydryl groups to sulfenic acid groups; reversible inactivation of tyrosine phosphatases by hydrogen peroxide is a common mechanism whereby generation of oxidants up-regulates tyrosine kinase signaling. ${ }^{15-20}$ 


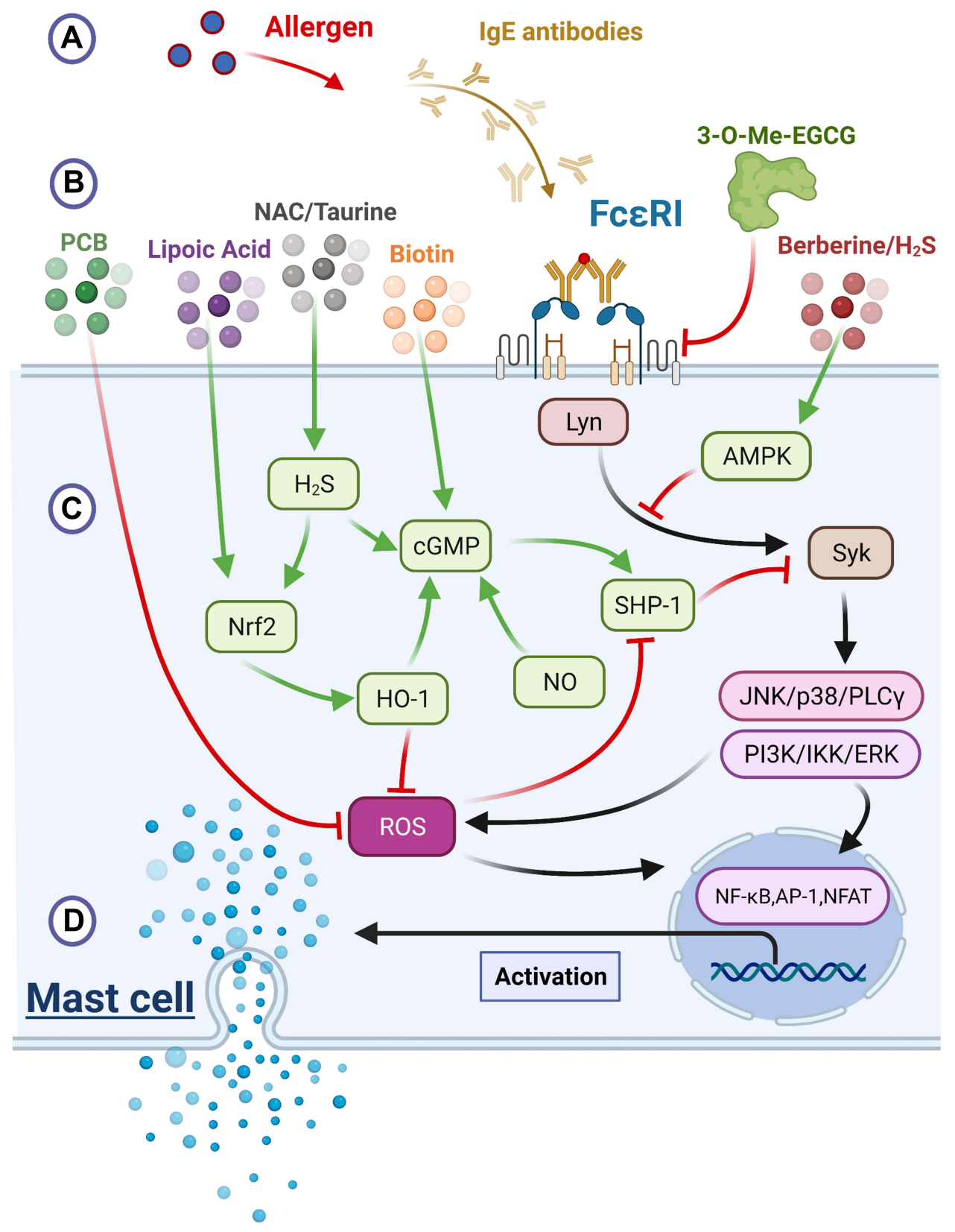

Figure I Mast cell activation: environmental stimulants, membrane receptors, intracellular signaling pathways and degranulation.

Notes: (A) Allergens, IgE antibodies and the Fc\&RI receptor. Interactions of antigenic allergens with IgE antibodies create acomplex that activates Fc\&RI receptor on the mast cell membrane. These initiate intracellular signaling pathways that result in the release of pro-inflammatory mediators and cytokines. (B) Nutraceuticals and their mode of action. The compound 3-O-Me-EGCG down-regulated the cell surface expression of FceRI, thus inducing mast cell stabilization. Biotin, berberine, $\mathrm{H}_{2} \mathrm{~S}$, PCB, lipoic acid and NAC, taurine, are agents that were found to have the clinical potential of allergy control by down-regulating these pathways. (C) Intracellular mediators and pathways. The mechanisms by which these agents may down-regulate pro-inflammatory activity are illustrated. Black arrows represent the up-regulation of pathways that were initiated by Fc\&RI interaction with antigen-lgE complex. Green arrows up-regulate and red arrows down-regulate, both act as anti-inflammatory by suppressing the black arrows pathways. In the signaling pathway following FceRI activation, Syk acts as acentral hub. Berberine/ $\mathrm{H}_{2} \mathrm{Scan}$ boost AMPK activity leading to Syk suppression, and SHP-I opposes Syk activity as well. Yet, following Syk activation, ROS reversibly inhibitsSHP-I. Biotin can boost cGMP levels, which enhances the activity of SHP-I. NAC/taurine can boost endogenous production of $\mathrm{H}_{2} \mathrm{~S}$, which up-regulates cGMP and stimulates Nrf2's transcriptional activity. Nrf2 promotes induction of HO-I which suppresses ROS and promotes cGMP production. Lipoic acid increases Nrf2 expression, and PCB has an inhibitory impact on ROS. (D) Degranulation. Downstream pathways, which were initiated by FcERI receptor, include the activation of PLC- $\gamma$, P38, JNK, PI3K, IKK, JNK and NADPH oxidase. The combination of these pathways promotes mast cell degranulation, while ramping up gene transcription and boosting synthesis of pro-inflammatory cytokines and lipid mediators. Created with BioRender.com.

Antigen activation of FceRI in mast cells has been shown to rapidly induce production of superoxide in the extracellular space. ${ }^{8}$ This effect is inhibited by wortmannin, diphenyleneiodonium, and apocynin - and hence points to membrane-bound NADPH oxidase as the superoxide source. Other research has determined that NOX2 is the predominant form of NADPH oxidase in mast cells. $^{21,22}$ Its activation may reflect PLC $\gamma$-mediated 
production of diacylglycerol (which in turn promotes PKC activity), and PI3K-mediated activation of Rac, likely via Bruton's tyrosine kinase (BTK) ${ }^{6,23,24}$ Importantly, inhibition of this initial burst of superoxide production suppresses antigen-stimulated mast cell degranulation. ${ }^{8}$ A likely explanation is that hydrogen peroxide generated near the plasma membrane inhibits SHP-1 activity, thereby up-regulating Syk-mediated tyrosine phosphorylation of the FecRI signaling complex. Several studies show that heme oxygenase-1 (HO-1) induction in mast cells opposes mast cell degranulation and activation; this may reflect, in part, the fact that the bilirubin generated by HO-1 functions as an inhibitor of NOX2-dependent NADPH oxidase activity. $^{25-32}$

\section{AMPK, Cyclic GMP, and Hydrogen Sulfide Down-Regulate Mast Cell Degranulation}

Several molecular mechanisms have been shown to inhibit antigen-stimulated mast cell degranulation. These include activation of AMP-activated kinase (AMPK), ${ }^{14,33-36}$ elevation of cyclic GMP (cGMP), ${ }^{37-39}$ and increased generation of hydrogen sulfide $\left(\mathrm{H}_{2} \mathrm{~S}\right) .{ }^{40-43}$ With respect to AMPK, this has been shown to suppress the association of Lyn and Syk with the FceRI receptor complex. ${ }^{44}$ While the basis of this effect has not yet been clarified, activated AMPK has been shown to confer a phosphorylation on the beta chain of this receptor; conceivably, this might suppress Lyn's ability to bind to this chain. ${ }^{44}$

With regard to cGMP, the cGMP-dependent protein kinase G II (PKGII) can confer an activating phosphorylation on the C-terminal region of SHP- $1 .{ }^{45}$ Whether the inhibitory impact of cGMP on mast cell degranulation reflects, in whole or in part, increased SHP-1 activity, requires further evaluation. The inhibitory effect of HO-1 activity on mast cell degranulation likely stems in part from the ability of carbon monoxide to promote cGMP production by soluble guanylate cyclase (sGC). ${ }^{46,47}$

Endogenous generation of $\mathrm{H}_{2} \mathrm{~S}$, as well as exposure to $\mathrm{H}_{2} \mathrm{~S}$-releasing drugs, have been shown to suppress mast cell degranulation. ${ }^{40-43}$ Several complementary mechanisms may contribute to this effect. In at least certain contexts, $\mathrm{H}_{2} \mathrm{~S}$ is capable of stimulating AMPK activity, via activation of calcium/calmodulin-dependent kinase kinase$\beta .^{48-51} \mathrm{H}_{2} \mathrm{~S}$, via S-sulfhydrations of Keap1 that blocks its binding to Nrf2 and thereby stimulate Nrf2's transcriptional activity, promotes induction of HO-1. ${ }^{52-55}$ And $\mathrm{H}_{2}$ $\mathrm{S}$ can also promote cGMP generation by reversing oxidative inhibition of sGC, as well as by inhibiting phosphodiesterase 5 (PDE5), which degrades cGMP in mast cells. ${ }^{56-58}$ In regard to the latter mechanism, the drug inhibitor of PDE5, vardenafil, has been reported to oppose mast cell degranulation. ${ }^{39}$

\section{Discussion on Nutraceutical Strategies for Mast Cell Stabilization}

The foregoing considerations offer a basis for proposing nutraceutical measures that could be expected to stabilize mast cells and thereby aid prevention and control of allergic reactions.

Berberine, a compound derived from certain medicinal herbs used in traditional Chinese medicine, is currently widely used in China both for glycemic control in type 2 diabetes, and as a hypolipidemic agent. ${ }^{59-61}$ Its clinical utility in diabetes has been traced to its ability to activate AMPK $^{62,63}$ - in that respect, its mechanism of action appears to be comparable to that of the drug metformin (which itself is a modification of herbal compounds with hypoglycemic activity). Berberine, in vitro, has been found to inhibit mast cell degranulation by suppressing Syk phosphorylation - precisely as would be predicted for an AMPK activator. ${ }^{64,65}$ In rodents, it has conferred protection in models of ovalbumin- or house-mite-induced allergic rhinitis, and in passive cutaneous anaphylaxis. ${ }^{65-67}$

Phase 2 inducing agents, via Nrf2-mediated induction of HO-1, could be expected to inhibit mast cell NADPH oxidase activity, as well as to boost cGMP via carbon monoxide generation. Lipoic acid and sulforaphane evolved from broccoli sprout extract (BSE) are phase 2 inducers with documented clinical utility. ${ }^{68-72}$ Lipoic acid has been found to be protective in rodent models of anaphylaxis, lessening histamine release, ${ }^{73-75}$ In a controlled clinical trial, ingestion of BSE was shown to benefit allergic rhinitis symptoms; another clinical study concluded that BSE ameliorated the nasal allergic response to inhalation of diesel exhaust particles. ${ }^{76,77}$ Melatonin can promote phase 2 induction by increasing Nrf2 expression; also, via induction of Sirt1, it can boost AMPK activity while antagonizing the NF-kappaB-mediated phase of mast cell activation. ${ }^{78-80}$ It has shown efficacy in ovalbumin-induced allergic rhinitis in rats, and has been found to suppress mast cell degranulation provoked by water avoidance stress. ${ }^{81,82}$ It also lessens inflammatory cytokine production by mast cells activated with phorbol ester and calcium ionophore, owing to downregulation of NF-kappaB signaling. ${ }^{83}$ 
While this discussion focuses on strategies for suppressing FceRI-mediated mast cell activation, it is of interest to note recent evidence that Nrf2 activation can also inhibit the MRFPRX2 signaling that mediates pseudo-allergic mast cell activation. ${ }^{84}$ Another agent with the potential for inhibiting both FceRI and MRFPRX2 signaling in mast cells is paeoniflorin, a bioactive component in peony flower extracts; the mast cell stabilizing action of this agent has been demonstrated both in mast cell cultures and in rodent allergy models. ${ }^{85-88}$ The direct molecular target of its action in this regard has yet to be defined.

Phycocyanobilin (PCB), a light-absorbing chromophore found in cyanobacteria (such as the food spirulina) and certain blue-green algae, is reduced within cells by biliverdin reductase to phycocaynorubin, a compound almost identical in secondary and tertiary structure to bilirubin. ${ }^{89,90}$ Not surprisingly, PCB has been shown to mimic bilirubin's inhibitory effect on NADPH oxidase complexes - a phenomenon, which may be largely responsible for the profound antioxidant and anti-inflammatory activities of orally administered spirulina (or of its protein phycocyanin, to which PCB is covalently bound) in a wide range of rodent models of health disorders. ${ }^{90-93}$ Indeed, oral administration of spirulina or phycocyanin has been found to alleviate symptoms and reduce histamine release in rat models of anaphylaxis induced by ovalbumin or compound 48/80; spirulina also stabilized mast cells and lessened symptoms in ovalbumin-induced allergic rhinitis. ${ }^{94-97}$ Small clinical trials with modest oral doses of spirulina have found it to confer symptomatic benefits in allergic rhinitis, and oral spirulina has also been shown to decrease interleukin-4 production by peripheral blood mononuclear cells stimulated ex vivo. ${ }^{98-100}$ The latter suggests that, independent of its impact on mast cells, spirulina might lessen the propensity to generate IgE.

In supraphysiological concentrations, which are achievable with practical and well-tolerated high-dose supplementation, the B vitamin biotin can directly activate sGC mimicking the physiological effects of nitric oxide and carbon monoxide in that regard. ${ }^{101-103}$ However, it is incapable of increasing sGC's activity by more than 2-3-fold - explaining why it cannot produce profound hypotension the way that NO overdoses can. The authors are unaware of any past effort to evaluate the impact of supraphysiological biotin concentrations on mast cell activation.

Endogenous production of $\mathrm{H}_{2} \mathrm{~S}$ can be boosted by supplemental $\mathrm{N}$-acetylcysteine (NAC), as cysteine is the preferred substrate for generation of $\mathrm{H}_{2} \mathrm{~S}$ by cystathionine $\beta$-synthase (CBS) and cystathionine $\gamma$-lyase (CSE). ${ }^{104-107}$ In addition, by promoting increased glutathione synthesis, NAC might help to counter the inhibitory effect of oxidants on SHP-1 activity, as glutathione acts to reverse the oxidative inhibition of this enzyme. ${ }^{17,108,109}$ In vascular tissues, supplemental taurine has recently been found to induce expression of both CBS and CSE. ${ }^{105,110,111}$ It is not clear whether taurine can have this effect in mast cells. However, taurine administration has been found to alleviate ovalbumin-induced allergic rhinitis in mice. ${ }^{112,113}$

A further resource for mast cell stabilization is offered by benifuuki tea, a cultivar of green tea that is unusually rich in an O-methylated form of the prominent green tea catechin epigallocatechin-gallate (EGCG); the site of methylation is on the 3"-hydroxyl of the gallate group. ${ }^{114}$ This type of tea has been shown to be clinically effective in seasonal allergies (Japanese cedar pollinosis), and its efficacy is thought to reflect the fact that O-methylated EGCG has far superior pharmacokinetics compared to EGCG per se. ${ }^{115-118}$ Both EGCG and O-methylated EGCG can stabilize mast cells in vitro, and this effect appears to be mediated through the high-affinity binding of these compounds to the $67 \mathrm{kDa}$ laminin receptor (67LR) on mast cells. ${ }^{114,119-126}$ How this receptor induces mast cell stabilization is at present poorly understood, although the interaction of EGCG with the laminin receptor is associated with down-regulated cell surface expression of FceRI. ${ }^{124}$ This effect is homologous to the ability of EGCG/67LR interaction to down-regulate the surface expression of epidermal growth factor receptors in cancer cells, an effect reflecting accelerated internalization of these receptors; perhaps EGCG likewise induces endosomal uptake of FceRI. ${ }^{127}$ Interaction of EGCG with 67LR also inhibits mast cell degranulation induced by calcium ionophores, blocking phosphorylation of myosin II regulatory light chain. ${ }^{125}$ And EGCG-mediated inhibition of NADPH oxidase assembly in stimulated mast cells has been reported. ${ }^{122}$ The clinical practicality of using 3-O-methyl EGCG to manage allergies would evidently be greater if polyphenol extracts of benifuuki tea were commercially available.

\section{Conclusions}

In summary, it can be concluded that nutraceutical regimens providing some or all of the following agents berberine, spirulina (or isolated PCB), lipoic acid (and/or broccoli sprouts), melatonin, NAC, taurine, high-dose biotin, benifuuki catechins - may have clinical potential for 
Table I Suggested Dose Schedules for Nutraceuticals with Potential for Opposing Mast Cell Degranulation

\begin{tabular}{|l|l|}
\hline Nutraceuticals & Dosage \\
\hline Spirulina & $\begin{array}{l}5-15 \text { g daily (or 30-100 mg } \\
\text { PCG daily) }\end{array}$ \\
\hline Lipoic acid & $600 \mathrm{mg}, 2-3$ times daily \\
\hline Broccoli Sprout Extract (Avmacol ${ }^{\text {TM}}$ ) & $375 \mathrm{mg}$ twice daily \\
\hline Berberine & $500 \mathrm{mg}$ twice daily \\
\hline Biotin & $10-20 \mathrm{mg}$, twice daily \\
\hline N-Acetylcysteine & $600 \mathrm{mg}, 2-3$ times daily \\
\hline Taurine & $2-3 \mathrm{~g}$ daily \\
\hline $\begin{array}{l}\text { Catechin-enriched Green Tea } \\
\text { Extract (Benifuuki) }\end{array}$ & $500 \mathrm{mg}$, twice daily \\
\hline
\end{tabular}

mast cell stabilization and allergy control. The mechanisms whereby these agents may down-regulate FceRI signaling are depicted in Figure 1. It would be of interest to study regimens of this sort in rodent models of allergy. It seems likely that a number of small effects that have a complementary impact could result in a substantial clinical benefit.

Table 1 suggests dose schedules of the various discussed nutraceuticals that might be expected to have some clinical impact. We do not represent these dose schedules as ideal for allergy management - rather, these are dose schedules that have shown clinical impact in other contexts, and hence might have potential to be active in allergy.

\section{Abbreviations}

SyK, spleen tyrosine kinase; $\mathrm{H}_{2} \mathrm{~S}$, Hydrogen sulfide; PCB, Phycocyanobilin; LAT, linker for activated T cells; PI3K, phosphatidylinositol-3-kinase; SHP-1, Src homology region 2 domain-containing phosphatase 1; BTK, Bruton's tyrosine kinase; HO-1, heme oxygenase-1; AMPK, AMP-activated kinase; cGMP, cyclic GMP; PKGII-cGMP, dependent protein kinase G II; sGC, soluble guanylate cyclase; PDE5, phosphodiesterase 5; BSE, broccoli sprout extract; NAC, N-acetylcysteine; CBS, cystathionine $\beta$-synthase; CSE, cystathionine $\gamma$-lyase; ROS, reactive oxygen species.

\section{Author Contributions}

All authors made substantial contributions to conception and design, acquisition of data, or analysis and interpretation of data; took part in drafting the article or revising it critically for important intellectual content; agreed to submit to the current journal; gave final approval for the version to be published; and agreed to be accountable for all aspects of the work.

\section{Disclosure}

Author MFM is co-inventor and co-owner of a patent covering nutraceutical uses of phycocyanobilin oligopeptides derived from spirulina. Author JJD is Director of Scientific Affairs for Advanced Ingredients for Dietary Products. The authors have no other conflicts of interest to disclose.

\section{References}

1. Dahlin JS, Maurer M, Metcalfe DD, Pejler G, Sagi-Eisenberg R, Nilsson G. The ingenious mast cell: contemporary insights into mast cell behavior and function. Allergy Eur $J$ Allergy Clin Immunol. 2021. doi:10.1111/all.14881

2. Varricchi G, Marone G. Mast cells: fascinating but still elusive after 140 years from their discovery. Int J Mol Sci. 2020;21 (464):464. doi:10.3390/ijms21020464

3. Giannetti A, Filice E, Caffarelli C, Ricci G, Pession A. Mast cell activation disorders. Med. 2021;57:124. doi:10.3390/medicina57 020124

4. Theoharides TC, Valent P, Akin C. Mast cells, mastocytosis, and related disorders. $N$ Engl J Med. 2015;373(2):163-172. doi:10. 1056/NEJMRA1409760

5. Dvorak A. Piecemeal degranulation of basophils and mast cells is effected by vesicular transport of stored secretory granule contents. Chem Immunol Allergy. 2005;85:135-184. doi:10.11 59/000086516

6. Metcalfe D, Peavy R, Gilfillan A. Mechanisms of mast cell signaling in anaphylaxis. J Allergy Clin Immunol. 2009;124 (4):639-646. doi:10.1016/J.JACI.2009.08.035

7. Blank U, Huang H, Kawakami T. The high affinity IgE receptor: a signaling update. Curr Opin Immunol. 2021;72:51-58. doi:10. 1016/J.COI.2021.03.015

8. Inoue T, Suzuki Y, Yoshimaru T, Ra C. Reactive oxygen species produced up- or downstream of calcium influx regulate proinflammatory mediator release from mast cells: role of NADPH oxidase and mitochondria. Biochim Biophys Acta Mol Cell Res. 2008;1783(5):789-802. doi:10.1016/J.BBAMCR.2007.12.004

9. Costello PS, Turner M, Walters AE, et al. Critical role for the tyrosine kinase Syk in signalling through the high affinity $\mathrm{IgE}$ receptor of mast cells. Oncogene. 1996;13(12):2595-2605.

10. Shao Y, Zhang S, Zhang Y, Liu Z. Recent advance of spleen tyrosine kinase in diseases and drugs. Int Immunopharmacol. 2021;90:107168. doi:10.1016/J.INTIMP.2020.107168

11. Nakata K, Yoshimaru T, Suzuki Y, et al. Positive and negative regulation of high affinity ige receptor signaling by src homology region 2 domain-containing phosphatase 1. J Immunol. 2008;181 (8):5414-5424. doi:10.4049/JIMMUNOL.181.8.5414

12. Gilfillan AM, Rivera J. The tyrosine kinase network regulating mast cell activation. Immunol Rev. 2009;228(1):149-169. doi:10. 1111/J.1600-065X.2008.00742.X

13. Mahajan A, Barua D, Cutler $P$, et al. Optimal aggregation of FceRI with a structurally defined trivalent ligand overrides negative regulation driven by phosphatases. ACS Chem Biol. 2014;9 (7):1508-1519. doi:10.1021/CB500134T 
14. Deng Y, Jin F, Li X, et al. Sauchinone suppresses FceRI-mediated mast cell signaling and anaphylaxis through regulation of LKB1/AMPK axis and SHP-1-Syk signaling module. Int Immunopharmacol. 2019;74:105702. doi:10.1016/J.INTIMP.2019.105702

15. Cunnick JM, Dorsey JF, Mei L, Wu J. Reversible regulation of SHP-1 tyrosine phosphatase activity by oxidation. IUBMB Life. 1998;45(5):887-894. doi:10.1002/IUB.7510450506

16. Weibrecht I, Böhmer SA, Dagnell M, Kappert K, Östman A, Böhmer FD. Oxidation sensitivity of the catalytic cysteine of the protein-tyrosine phosphatases SHP-1 and SHP-2. Free Radic Biol Med. 2007;43(1):100-110. doi:10.1016/J.FREERADBIOMED.20 07.03.021

17. Chen C-Y, Willard D, Rudolph J. Redox regulation of SH2-domaincontaining protein tyrosine phosphatases by two backdoor cysteines. Biochemistry. 2009;48(6):1399-1409. doi:10.1021/BI801973Z

18. Heneberg $\mathrm{P}$, Dráberová L, Bambousková $\mathrm{M}$, Pompach $\mathrm{P}$, Dráber P. Down-regulation of protein-tyrosine phosphatases activates an immune receptor in the absence of its translocation into lipid rafts. J Biol Chem. 2010;285(17):12787-12802. doi:10.10 74/JBC.M109.052555

19. Tanner JJ, Parsons ZD, Cummings AH, Zhou H, Gates KS. Redox regulation of protein tyrosine phosphatases: structural and chemical aspects. Antioxid Redox Signal. 2011;15(1):77-97. doi:10.1089/ARS.2010.3611

20. Lo Conte M, Carroll KS. The redox biochemistry of protein sulfenylation and sulfinylation. $J$ Biol Chem. 2013;288 (37):26480-26488. doi:10.1074/JBC.R113.467738

21. Li ZY, Jiang WY, Cui ZJ. An essential role of NAD(P)H oxidase 2 in UVA-induced calcium oscillations in mast cells. Photochem Photobiol Sci. 2015;14(2):414-428. doi:10.1039/C4PP00304G

22. Min A, Lee YA, Kim KA, Shin MH. BLT1-mediated O-GlcNAcylation is required for NOX2-dependent migration, exocytotic degranulation and IL-8 release of human mast cell induced by Trichomonas vaginalis-secreted LTB4. Microbes Infect. 2018;20(6):376-384. doi:10.1016/J.MICINF.2018.05.005

23. Kuehn HS, Rådinger M, Brown JM, et al. Btk-dependent Rac activation and actin rearrangement following FceRI aggregation promotes enhanced chemotactic responses of mast cells. J Cell Sci. 2010;123(15):2576-2585. doi:10.1242/JCS.071043

24. Rastogi R, Geng X, Li F, Ding Y. NOX activation by subunit interaction and underlying mechanisms in disease. Front Cell Neurosci. 2017;301. doi:10.3389/FNCEL.2016.00301

25. Takamiya R, Murakami M, Kajimura M, et al. Stabilization of mast cells by heme oxygenase-1: an anti-inflammatory role. Am J Physiol Hear Circ Physiol. 2002;283(3):H861-H870. doi:10.11 52/AJPHEART.00740.2001

26. Yasui Y, Nakamura M, Onda T, et al. Heme oxygenase-1 inhibits cytokine production by activated mast cells. Biochem Biophys Res Commun. 2007;354(2):485-490. doi:10.1016/J.BBRC.2006.12.228

27. Matsushima M, Takagi K, Ogawa M, et al. Heme oxygenase-1 mediates the anti-allergic actions of quercetin in rodent mast cells. Inflamm Res. 2009;58(10):705-715. doi:10.1007/S00011-009-00 39-1

28. Ma Y, Yang M, Wang C, Ding J, Li J. Inhibiting mast cell degranulation by HO-1 affects dendritic cell maturation in vitro. Inflamm Res. 2014;63(7):527-537. doi:10.1007/S00011-0140722-8

29. Lanone S, Bloc S, Foresti R, et al. Bilirubin decreases NOS2 expression via inhibition of $\mathrm{NAD}(\mathrm{P}) \mathrm{H}$ oxidase: implications for protection against endotoxic shock in rats. FASEB J. 2005;19 (13):1890-1892. doi:10.1096/FJ.04-2368FJE

30. Matsumoto H, Ishikawa K, Itabe H, Maruyama Y. Carbon monoxide and bilirubin from heme oxygenase-1 suppresses reactive oxygen species generation and plasminogen activator inhibitor-1 induction. Mol Cell Biochem. 2006;291(1):21-28. doi:10.1007/ S11010-006-9190-Y
31. Jiang F, Roberts SJ, Datla S, Dusting GJ. NO modulates NADPH oxidase function via heme oxygenase-1 in human endothelial cells. Hypertension. 2006;48(5):950-957. doi:10.1161/01.HYP.00 00242336.58387.1F

32. Datla SR, Dusting GJ, Mori TA, Taylor CJ, Croft KD, Jiang F. Induction of heme oxygenase-1 in vivo suppresses NADPH oxidase-derived oxidative stress. Hypertension. 2007;50(4):6 36-642. doi:10.1161/HYPERTENSIONAHA.107.092296

33. Hwang SL, Li X, Lu Y, et al. AMP-activated protein kinase negatively regulates FceRI-mediated mast cell signaling and anaphylaxis in mice. J Allergy Clin Immunol. 2013;132(3):729-736. e12. doi:10.1016/J.JACI.2013.02.018

34. Hwang SL, Lu Y, Li X, et al. ERK1/2 antagonize AMPKdependent regulation of FceRI-mediated mast cell activation and anaphylaxis. J Allergy Clin Immunol. 2014;134(3):714-721.e7. doi:10.1016/J.JACI.2014.05.001

35. Li X, Park SJ, Jin F, et al. Tanshinone IIA suppresses FceRImediated mast cell signaling and anaphylaxis by activation of the Sirt1/LKB1/AMPK pathway. Biochem Pharmacol. 2018;15 2:362-372. doi:10.1016/J.BCP.2018.04.015

36. Wang C, Li L, Jiang J, et al. Pterostilbene inhibits FceRI signaling through activation of the LKB1/AMPK pathway in allergic response. J Agric Food Chem. 2020;68(11):3456-3465. doi:10.10 21/ACS.JAFC.9B07126

37. Masini E, Mannaioni PF, Pistelli A, Salvemini D, Vane J. Impairment of the L-arginine-nitric oxide pathway in mast cells from spontaneously hypertensive rats. Biochem Biophys Res Commun. 1991;177(3):1178-1182. doi:10.1016/0006-291X(91) 90664-S

38. Yip KH, Huang Y, Leung FP, Lau HYA. Cyclic guanosine monophosphate dependent pathway contributes to human mast cell inhibitory actions of the nitric oxide donor, diethylamine NONOate. Eur J Pharmacol. 2010;632(1-3):86-92. doi:10.101 6/J.EJPHAR.2010.01.007

39. El-Awady MS, Eman S. Vardenafil ameliorates immunologic- and non-immunologic-induced allergic reactions. Can J Physiol Pharmacol. 2014;92(3):175-180. doi:10.1139/CJPP-2013-0316

40. Liu Y-H, Lu M, Xie Z-Z. Hydrogen sulfide prevents heart failure development via inhibition of renin release from mast cells in isoproterenol-treated rats. Antioxid Redox Signal. 2014;20 (5):759-769. doi:10.1089/ARS.2012.4888

41. Roviezzo F, Bertolino A, Sorrentino R, et al. Hydrogen sulfide inhalation ameliorates allergen induced airway hyperreactivity by modulating mast cell activation. Pharmacol Res. 2015;100:85-92. doi:10.1016/J.PHRS.2015.07.032

42. Marino A, Martelli A, Citi V, et al. The novel $\mathrm{H}_{2} \mathrm{~S}$ donor 4-carboxy-phenyl isothiocyanate inhibits mast cell degranulation and renin release by decreasing intracellular calcium. $\mathrm{Br}$ J Pharmacol. 2016;173(22):3222-3234. doi:10.1111/BPH.13583

43. Rodrigues L, Ekundi-Valentim E, Florenzano J, et al. Protective effects of exogenous and endogenous hydrogen sulfide in mast cell-mediated pruritus and cutaneous acute inflammation in mice. Pharmacol Res. 2017;115:255-266. doi:10.1016/J.PHRS.2016. 11.006

44. Lin K-C, Huang D-Y, Huang D-W, Tzeng S-J, Lin -W-W. Inhibition of AMPK through Lyn-Syk-Akt enhances FceRI signal pathways for allergic response. J Mol Med. 2015;94(2):183-194. doi:10.1007/S00109-015-1339-2

45. Rangaswami H, Schwappacher R, Marathe N, et al. Cyclic GMP and protein kinase $\mathrm{G}$ control a Src-containing mechanosome in osteoblasts. Sci Signal. 2010;3(153):ra91-ra91. doi:10.1126/ SCISIGNAL. 2001423

46. Brüne B, Schmidt K-U, Ullrich V. Activation of soluble guanylate cyclase by carbon monoxide and inhibition by superoxide anion. Eur J Biochem. 1990;192(3):683-688. doi:10.1111/J.1432-1033. 1990.TB19276.X 
47. Siow RCM, Sato H, Mann GE. Heme oxygenase-carbon monoxide signalling pathway in atherosclerosis: anti-atherogenic actions of bilirubin and carbon monoxide? Cardiovasc Res. 1999;41(2):385-394. doi:10.1016/S0008-6363(98)00278-8

48. Lee HJ, Mariappan MM, Feliers D, et al. Hydrogen sulfide inhibits high glucose-induced matrix protein synthesis by activating AMP-activated protein kinase in renal epithelial cells. $J$ Biol Chem. 2012;287(7):4451-4461. doi:10.1074/JBC.M111.278325

49. Chen X, Zhao X, Lan F, et al. Hydrogen sulphide treatment increases insulin sensitivity and improves oxidant metabolism through the CaMKKbeta-AMPK pathway in PA-induced IR C2C12 cells. Sci Rep. 2017;7(1):1-13. doi:10.1038/s41598-017-13251-0

50. Chen X, Zhao X, Cai H, et al. The role of sodium hydrosulfide in attenuating the aging process via PI3K/AKT and CaMKK $\beta$ / AMPK pathways. Redox Biol. 2017;12:987-1003. doi:10.1016/J. REDOX.2017.04.031

51. Zhou X, Cao Y, Ao G, et al. CaMKK $\beta$-dependent activation of AMP-activated protein kinase is critical to suppressive effects of hydrogen sulfide on neuroinflammation. Antioxid Redox Signal. 2014;21(12):1741-1758. doi:10.1089/ARS.2013.5587

52. Hourihan JM, Kenna JG, Hayes JD. The gasotransmitter hydrogen sulfide induces Nrf2-target genes by inactivating the Keap1 ubiquitin ligase substrate adaptor through formation of a disulfide bond between Cys-226 and Cys-613. Antioxid Redox Signal. 2013;19(5):465-481. doi:10.1089/ARS.2012.4944

53. Yang G, Zhao K, Ju Y, et al. Hydrogen sulfide protects against cellular senescence via S-sulfhydration of Keap1 and activation of Nrf2. Antioxid Redox Signal. 2013;18(15):1906-1919. doi:10.10 89/ARS.2012.4645

54. Yang H, Mao Y, Tan B, Luo S, Zhu Y. The protective effects of endogenous hydrogen sulfide modulator, S-propargyl-cysteine, on high glucose-induced apoptosis in cardiomyocytes: a novel mechanism mediated by the activation of Nrf2. Eur J Pharmacol. 2015;761:135-143. doi:10.1016/J.EJPHAR.2015. 05.001

55. Xie L, Gu Y, Wen M, et al. Hydrogen sulfide induces Keap1 S-sulfhydration and suppresses diabetes-accelerated atherosclerosis via Nrf2 activation. Diabetes. 2016;65(10):3171-3184. doi:10. 2337/DB16-0020

56. Szabo C. Hydrogen sulfide, an enhancer of vascular nitric oxide signaling: mechanisms and implications. Am J Physiol Cell Physiol. 2017;312(1):C3-C15. doi:10.1152/AJPCELL.00282.2016

57. Nalli AD, Bhattacharya S, Wang $\mathrm{H}$, Kendig DM, Grider JR, Murthy KS. Augmentation of cGMP/PKG pathway and colonic motility by hydrogen sulfide. Am J Physiol Gastrointest Liver Physiol. 2017;313(4):G330-G341. doi:10.1152/AJPGI.00161. 2017

58. Zhou Z, Martin E, Sharina I, et al. Regulation of soluble guanylyl cyclase redox state by hydrogen sulfide. Pharmacol Res. 2016;111:556-562. doi:10.1016/J.PHRS.2016.06.029

59. Liang Y, Xu X, Yin $\mathrm{M}$, et al. Effects of berberine on blood glucose in patients with type 2 diabetes mellitus: a systematic literature review and a meta-analysis. Endocr J. 2019;66 (1):51-63. doi:10.1507/ENDOCRJ.EJ18-0109

60. Ju J, Li J, Lin Q, Xu H. Efficacy and safety of berberine for dyslipidaemias: a systematic review and meta-analysis of randomized clinical trials. Phytomedicine. 2018;50:25-34. doi:10.1016/ J.PHYMED.2018.09.212

61. Ye Y, Liu X, Wu N, et al. Efficacy and safety of berberine alone for several metabolic disorders: a systematic review and meta-analysis of randomized clinical trials. Front Pharmacol. 2021;12. doi:10.3389/FPHAR.2021.653887

62. Lee YS, Kim WS, Kim KH, et al. Berberine, a natural plant product, activates AMP-activated protein kinase with beneficial metabolic effects in diabetic and insulin-resistant states. Diabetes. 2006;55(8):2256-2264. doi:10.2337/DB06-0006
63. Turner N, Li J-Y, Gosby A, et al. Berberine and its more biologically available derivative, dihydroberberine, inhibit mitochondrial respiratory complex I. Diabetes. 2008;57(5):1414-1418. doi:10.2337/DB07-1552

64. Song Y, Qu C, Srivastava K, et al. Food allergy herbal formula 2 protection against peanut anaphylactic reaction is via inhibition of mast cells and basophils. J Allergy Clin Immunol. 2010;126 (6):1208-1217.e3. doi:10.1016/J.JACI.2010.09.013

65. Fu S, Ni S, Wang D, Fu M, Hong T. Berberine suppresses mast cell-mediated allergic responses via regulating FceRI-mediated and MAPK signaling. Int Immunopharmacol. 2019;71:1-6. doi:10.1016/J.INTIMP.2019.02.041

66. Kim BY, Park HR, Jeong HG, Kim SW. Berberine reduce allergic inflammation in a house dust mite allergic rhinitis mouse model. Rhinol J. 2015;53(4):353-358. doi:10.4193/RHIN15.028

67. Sakat MS, Kilic K, Kandemir FM, et al. The ameliorative effect of berberine and coenzyme Q10 in an ovalbumin-induced allergic rhinitis model. Eur Arch Otorhinolaryngol. 2018;275(10):24 95-2505. doi:10.1007/S00405-018-5104-3

68. Koriyama Y, Nakayama Y, Matsugo S, Kato S. Protective effect of lipoic acid against oxidative stress is mediated by Keap1/ Nrf2-dependent heme oxygenase-1 induction in the RGC-5 celline. Brain Res. 2013;1499:145-157. doi:10.1016/J.BRAINRES. 2012.12.041

69. Kyung S, Lim Joo W, Kim H. $\alpha$-Lipoic acid inhibits IL-8 expression by activating $\mathrm{Nrf} 2$ signaling in helicobacter pylori-infected gastric epithelial cells. Nutrients. 2019;11(10):2524. doi:10.3390/ NU11102524

70. Jeffrey S, Samraj P, Raj B. The role of alpha-lipoic acid supplementation in the prevention of diabetes complications: a comprehensive review of clinical trials. Curr Diabetes Rev. 2021;17. doi:10.2174/1573399817666210118145550

71. Kensler TW, Egner PA, Agyeman AS, et al. Keap1-nrf2 signaling: a target for cancer prevention by sulforaphane. Top Curr Chem. 2013;329:163-177. doi:10.1007/128_2012_339

72. Riedl MA, Saxon A, Diaz-Sanchez D. Oral sulforaphane increases phase II antioxidant enzymes in the human upper airway. Clin Immunol. 2009;130(3):244-251. doi:10.1016/J. CLIM.2008.10.007

73. Choi YH, Chai OH, Han E-H, Choi S-Y, Kim HT, Song CH. Lipoic acid suppresses compound 48/80-induced anaphylaxis-like reaction. Anat Cell Biol. 2010;43(4):317. doi:10.5115/ACB.20 10.43.4.317

74. Ma X, He P, Sun P, Han P. Lipoic acid: an immunomodulator that attenuates glycinin-induced anaphylactic reactions in a rat model. J Agric Food Chem. 2010;58(8):5086-5092. doi:10.1021/JF904403U

75. Van Nguyen T, Piao CH, Fan YJ, et al. Anti-allergic rhinitis activity of $\alpha$-lipoic acid via balancing Th17/Treg expression and enhancing Nrf2/HO-1 pathway signaling. Sci Rep. 2020;10 (1):1-13. doi:10.1038/s41598-020-69234-1

76. Yusin J, Wang V, Henning SM, et al. The effect of broccoli sprout extract on seasonal grass pollen-induced allergic rhinitis. Nutrients. 2021;13(4):1337. doi:10.3390/NU13041337

77. David H, Zhaoping L, Maria G-L, et al. Sulforaphane-rich broccoli sprout extract attenuates nasal allergic response to diesel exhaust particles. Food Funct. 2013;5(1):35-41. doi:10.1039/C3FO60277J

78. Fang J, Yan Y, Teng X, et al. Melatonin prevents senescence of canine adipose-derived mesenchymal stem cells through activating NRF2 and inhibiting ER stress. Aging (Albany NY). 2018;10 (10):2954. doi:10.18632/AGING.101602

79. Hardeland R. Melatonin and inflammation - story of a double-edged blade. J Pineal Res. 2018;65(4):e12525. doi:10.1111/JPI.12525

80. Merlo S, Luaces JP, Spampinato SF, et al. SIRT1 mediates melatonin's effects on microglial activation in hypoxia: in vitro and in vivo evidence. Biomolecules. 2020;10(3):364. doi:10.3390/ BIOM10030364 
81. Cakir Cetin A, Ecevit MC, Gumustekin M, et al. Therapeutic effects of melatonin on an ovalbumin-induced allergic rhinitis model in rats. Auris Nasus Larynx. 2021;48(6):1109-1119. doi:10.1016/J.ANL.2021.04.010

82. Çikler E, Ercan F, Çetinel Ş, Contuk G, Şener G. The protective effects of melatonin against water avoidance stress-induced mast cell degranulation in dermis. Acta Histochem. 2005;106 (6):467-475. doi:10.1016/J.ACTHIS.2004.10.001

83. Maldonado MD, García-Moreno H, González-Yanes C, Calvo JR. Possible involvement of the inhibition of NF- $\kappa \mathrm{B}$ factor in antiinflammatory actions that melatonin exerts on mast cells. $J$ Cell Biochem. 2016;117(8):1926-1933. doi:10.1002/JCB.25491

84. Wang J, Zhang Y, Hu S, Ge S, Jia M, Wang N. Resveratrol inhibits MRGPRX2-mediated mast cell activation via Nrf2 pathway. Int Immunopharmacol. 2021;93:107426. doi:10.1016/J. INTIMP.2021.107426

85. Zhang Y, Hu S, Ge S, Wang J, He L. Paeoniflorin inhibits IgEmediated allergic reactions by suppressing the degranulation of mast cells though binding with FceRI alpha subunits. Eur J Pharmacol. 2020;886:173415. doi:10.1016/J.EJPHAR.2020.173415

86. Wang G, Cheng N. Paeoniflorin inhibits mast cell-mediated allergic inflammation in allergic rhinitis. $J$ Cell Biochem. 2018;119(10):8636-8642. doi:10.1002/JCB.27135

87. Wang J, Zhang Y, Wang J, et al. Paeoniflorin inhibits MRGPRX2-mediated pseudo-allergic reaction via calcium signaling pathway. Phyther Res. 2020;34(2):401-408. doi:10.1002/PTR.6531

88. Zhao Y, Li X, Chu J, et al. Inhibitory effect of paeoniflorin on IgE-dependent and IgE-independent mast cell degranulation: in vitro and vivo. Food Funct. 2021;12(16):7448-7468. doi:10. 1039/D1FO01421H

89. Terry MJ, Maines MD, Lagarias JC. Inactivation of phytochromeand phycobiliprotein-chromophore precursors by rat liver biliverdin reductase. J Biol Chem. 1993;268(35):26099-26106. doi:10. 1016/S0021-9258(19)74286-0

90. McCarty MF. Clinical potential of spirulina as a source of phycocyanobilin. J Med Food. 2007;10(4):566-570. doi:10. 1089/JMF.2007.621

91. Zheng J, Inoguchi T, Sasaki S, et al. Phycocyanin and phycocyanobilin from Spirulina platensis protect against diabetic nephropathy by inhibiting oxidative stress. Am J Physiol Regul Integr Comp Physiol. 2013;304(2):R110-R120. doi:10.1152/AJPREGU. 00648.2011

92. Liu Q, Huang Y, Zhang R, Cai T, Cai Y. Medical application of spirulina platensis derived C-phycocyanin. Evid Based Complement Altern Med. 2016;2016. doi:10.1155/2016/7803846

93. Wu Q, Liu L, Miron A, Klímová B, Wan D, Kuča K. The antioxidant, immunomodulatory, and anti-inflammatory activities of spirulina: an overview. Arch Toxicol. 2016;90(8):1817-1840. doi:10.1007/S00204-016-1744-5

94. Yang H-N, Lee E-H, Kim H-M. Spirulina platensis inhibits anaphylactic reaction. Life Sci. 1997;61(13):1237-1244. doi:10.1016/ S0024-3205(97)00668-1

95. Kim HM, Lee EH, Cho HH, Moon YH. Inhibitory effect of mast cell-mediated immediate-type allergic reactions in rats by spirulina. Biochem Pharmacol. 1998;55(7):1071-1076. doi:10. 1016/S0006-2952(97)00678-3

96. Remirez D, Ledón N, González R. Role of histamine in the inhibitory effects of phycocyanin in experimental models of allergic inflammatory response. Mediators Inflamm. 2002;11 (2):81-85. doi:10.1080/09629350220131926

97. Chen LL, Zhang SF, Huang DN, Tan JQ, He SH. Experimental study of spirulina platensis in treating allergic rhinitis in rats. J Cent South Univ). 2005;30(1):96-98.

98. Cingi C, Conk-Dalay M, Cakli H, Bal C. The effects of spirulina on allergic rhinitis. Eur Arch Otorhinolaryngol. 2008;265 (10):1219-1223. doi:10.1007/S00405-008-0642-8
99. Nourollahian M, Rasoulian B, Gafari A, Anoushiravani M, Jabari F, Bakhshaee M. Clinical comparison of the efficacy of spirulina platensis and cetirizine for treatment of allergic rhinitis. Acta Otorhinolaryngol Ital. 2020;40(3):224-229. doi:10.14639/ 0392-100X-N0139

100. Mao TK, Van De Water J, Gershwin ME. Effects of a Spirulina-based dietary supplement on cytokine production from allergic rhinitis patients. J Med Food. 2005;8(1):27-30. doi:10. 1089/JMF.2005.8.27

101. Vesely D. Biotin enhances guanylate cyclase activity. Science. 1982;216(4552):1329-1330. doi:10.1126/SCIENCE.6123152

102. Watanabe-Kamiyama M, Kamiyama S, Horiuchi K, et al. Antihypertensive effect of biotin in stroke-prone spontaneously hypertensive rats. Br J Nutr. 2008;99(4):756-763. doi:10.1017/ S0007114507841122

103. McCarty MF, DiNicolantonio JJ. Neuroprotective potential of high-dose biotin. Med Hypotheses. 2017;109:145-149. doi:10. 1016/J.MEHY.2017.10.012

104. Ezeriņa D, Takano Y, Hanaoka K, Urano Y, Dick TP. N-acetyl cysteine functions as a fast-acting antioxidant by triggering intracellular H $2 \mathrm{~S}$ and sulfane sulfur production. Cell Chem Biol. 2018;25(4):447-459.e4. doi:10.1016/J.CHEMBIOL.2018. 01.011

105. Dinicolantonio JJ, Okeefe JH, McCarty MF. Boosting endogenous production of vasoprotective hydrogen sulfide via supplementation with taurine and $\mathrm{N}$-acetylcysteine: a novel way to promote cardiovascular health. Open Heart. 2017;4(1):e000600. doi:10.1136/ OPENHRT-2017-000600

106. Zuhra K, Tomé CS, Masi L, et al. N-acetylcysteine serves as substrate of 3-mercaptopyruvate sulfurtransferase and stimulates sulfide metabolism in colon cancer cells. Cells. 2019;8(8):828. doi:10.3390/CELLS8080828

107. Bourgonje AR, Offringa AK, van Eijk LE, et al. N-acetylcysteine and hydrogen sulfide in coronavirus disease 2019. Antioxid Redox Signal. 2021. doi:10.1089/ARS.2020.8247

108. Atkuri KR, Mantovani JJ, Herzenberg LA, Herzenberg LA. $\mathrm{N}$-acetylcysteine-a safe antidote for cysteine/glutathione deficiency. Curr Opin Pharmacol. 2007;7(4):355-359. doi:10.10 16/J.COPH.2007.04.005

109. Dodd S, Dean O, Copolov DL, Malhi GS, Berk M. $\mathrm{N}$-acetylcysteine for antioxidant therapy: pharmacology and clinical utility. Expert Opin Biol Ther. 2008;8(12):1955-1962. doi:10. $1517 / 14728220802517901$

110. Sun Q, Wang B, Li Y, et al. Taurine supplementation lowers blood pressure and improves vascular function in prehypertension: Randomized, Double-Blind, Placebo-Controlled Study. Hypertension. 2016;67(3):541-549. doi:10.1161/ HYPERTENSIONAHA.115.06624

111. Guizoni DM, Freitas IN, Victorio JA, et al. Taurine treatment reverses protein malnutrition-induced endothelial dysfunction of the pancreatic vasculature: the role of hydrogen sulfide. Metabolism. 2021;116:154701. doi:10.1016/J.METABOL.2021. 154701

112. Nam SY, Kim HM, Jeong HJ. The potential protective role of taurine against experimental allergic inflammation. Life Sci. 2017;184:18-24. doi:10.1016/J.LFS.2017.07.007

113. Zhou J, Lu Y, Li F, Wu W, Xie D, Feng Y. In vitro and in vivo antiallergic effects of taurine on allergic rhinitis. Int Arch Allergy Immunol. 2020;181(6):404-416. doi:10.1159/00050 5209

114. Maeda Yamamoto M, Ema K, Monobe M, Tokuda Y, Tachibana H. Epicatechin-3-O-(3"-O-methyl)-gallate content in various tea cultivars (Camellia sinensis L.) and its in vitro inhibitory effect on histamine release. J Agric Food Chem. 2012;60 (9):2165-2170. doi:10.1021/JF204497B 
115. Masuda S, Maeda-Yamamoto M, Usui S, Fujisawa T. "Benifuuki" green tea containing O-methylated catechin reduces symptoms of Japanese cedar pollinosis: a randomized, double- blind, placebo-controlled trial. Allergol Int. 2014;63(2):211-217. doi:10.2332/ALLERGOLINT.13-OA $-0620$

116. Maeda-Yamamoto M, Ema K, Monobe M, et al. The efficacy of early treatment of seasonal allergic rhinitis with benifuuki green tea containing O-methylated catechin before pollen exposure: an Open Randomized Study. Allergol Int. 2009;58(3):437-444. doi:10.2332/ ALLERGOLINT.08-OA-0066

117. Oritani Y, Setoguchi Y, Ito R, Maruki-Uchida H, Ichiyanagi T, Ito T. Comparison of (-)-epigallocatechin-3-O-gallate (EGCG) and O-methyl EGCG bioavailability in rats. Biol Pharm Bull. 2013;36(10):1577-1582. doi:10.1248/BPB.B1300349

118. Maeda-Yamamoto M, Ema K, Tokuda Y, et al. Effect of green tea powder (Camellia sinensis L. cv. Benifuuki) particle size on O-methylated EGCG absorption in rats; the Kakegawa Study. Cytotechnology. 2011;63(2):171-179. doi:10.1007/S10616-0109331-8

119. Inoue T, Suzuki Y, Ra C. Epigallocatechin-3-gallate inhibits mast cell degranulation, leukotriene $\mathrm{C} 4$ secretion, and calcium influx via mitochondrial calcium dysfunction. Free Radic Biol Med. 2010;49(4):632-640. doi:10.1016/J.FREERADBIOMED. 2010.05.015

120. Yamashita K, Suzuki Y, Matsui T, et al. Epigallocatechin gallate inhibits histamine release from rat basophilic leukemia (RBL-2H3) cells: role of tyrosine phosphorylation pathway. Biochem Biophys Res Commun. 2000;274(3):603-608. doi:10.1006/BBRC.2000.3200
121. Fujimura Y, Tachibana H, Maeda-Yamamoto M, Miyase T, Sano M, Yamada K. Antiallergic tea catechin, (-)epigallocatechin-3-O-(3-O-methyl)-gallate, suppresses FceRl expression in human basophilic KU812 cells. J Agric Food Chem. 2002;50(20):5729-5734. doi:10.1021/JF025680Z

122. Nishikawa H, Wakano K, Kitani S. Inhibition of NADPH oxidase subunits translocation by tea catechin EGCG in mast cell. Biochem Biophys Res Commun. 2007;362(2):504-509. doi:10.1016/J.BBRC.2007.08.015

123. Fujimura Y, Sumida M, Sugihara K, Tsukamoto S, Yamada K, Tachibana H. Green tea polyphenol EGCG sensing motif on the 67-kDa laminin receptor. PLoS One. 2012;7(5):5. doi:10.1371/ JOURNAL.PONE.0037942

124. Fujimura Y, Yamada K, Tachibana H. A lipid raft-associated 67 kDa laminin receptor mediates suppressive effect of epigallocatechin3-O-gallate on FceRI expression. Biochem Biophys Res Commun. 2005;336(2):674-681. doi:10.1016/J.BBRC.2005.08.146

125. Fujimura Y, Umeda D, Kiyohara Y, Sunada Y, Yamada K, Tachibana $H$. The involvement of the $67 \mathrm{kDa}$ laminin receptor-mediated modulation of cytoskeleton in the degranulation inhibition induced by epigallocatechin-3-O-gallate. Biochem Biophys Res Commun. 2006;348(2):524-531. doi:10.1016/J. BBRC.2006.07.086

126. Fujimura Y, Umeda D, Yano S, Maeda-Yamamoto M, Yamada K, Tachibana $\mathrm{H}$. The $67 \mathrm{kDa}$ laminin receptor as a primary determinant of anti-allergic effects of O-methylated EGCG. Biochem Biophys Res Commun. 2007;364(1):79-85. doi:10.1016/J.BBRC.2007.09.095

127. Adachi S, Nagao T, To S, et al. (-)-Epigallocatechin gallate causes internalization of the epidermal growth factor receptor in human colon cancer cells. Carcinogenesis. 2008;29(10):1986-1993. doi:10.1093/CARCIN/BGN128

\section{Publish your work in this journal}

The Journal of Asthma and Allergy is an international, peer-reviewed open-access journal publishing original research, reports, editorials and commentaries on the following topics: Asthma; Pulmonary physiology; Asthma related clinical health; Clinical immunology and the immunological basis of disease; Pharmacological interventions and new therapies. The manuscript management system is completely online and includes a very quick and fair peer-review system, which is all easy to use. Visit http://www.dovepress.com/testimonials.php to read real quotes from published authors. 